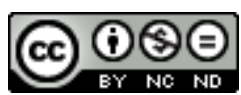

Revista Pax Domini é licenciada sob uma Licença Creative Commons.

\title{
ANOTAÇÕES SOBRE CRISTOLOGIA NO PENSAMENTO DE BONHOEFFER
}

\author{
Carlos Caldas ${ }^{1}$
}

\begin{abstract}
RESUMO
Este artigo visa apresentar, posto que em síntese, observações sobre como o teólogo luterano alemão Dietrich Bonhoeffer (1906-1945), sem dúvida um dos mais influentes e importantes pensadores cristãos do século XX, articulou sua compreensão cristológica. Apresentar-se-ão também algumas implicações missiológicas derivadas da maneira pela qual Bonhoeffer entendia a pessoa e a obra de Cristo.
\end{abstract}

\section{Palavras-Chave}

Estudos bonhoefferianos, Cristologia, Concílio de Calcedônia, Teologia da Reforma, Missão da igreja

\begin{abstract}
This essay intends to present, even briefly, some observation on how the German Lutheran theologian Dietrich Bonhoeffer (1906-1945), without doubt, one of most influent and important Christian thinkers of 20th century, developed his understanding of Christology. It will also presented some missiological implications dervied from the way Bonhoeffer understood the person and work of Christ.
\end{abstract}

\section{Keywords}

Bonhoefferian studies, Christology, Council of Chalcedon, Theology of the Reformation, Mission of the Church

${ }^{1}$ Carlos Caldas, doutor em Ciências da Religião pela Universidade Metodista de São Paulo, é Bolsista PNPD-CAPES na Faculdade Jesuíta de Filosofia e Teologia (Belo Horizonte, MG). E-mail de contato: crcaldas2009@ hotmail.com

Revista Pax Domini | Faculdade Boas Novas | v. 1 | p. 22 - 31 | jun. 2015 


\section{INTRODUÇÃO}

Cristologia é o nome que se dá na tradição da teologia sistemática ao estudo da pessoa e obra de Cristo. "Quem diz o povo ser o Filho do homem? Uns dizem que tu és... outros que és... E vós, continuou ele, quem dizeis que eu sou?". Pode-se dizer que toda a história da cristologia é uma tentativa de responder aos questionamentos feitos pelo próprio Cristo aos seus seguidores - "O que dizem de mim? E vós, quem dizeis que eu sou?"2. As assim chamadas controvérsias cristológicas dos primeiros séculos da história da igreja cristã revelam que não foi fácil para os primeiros seguidores de Jesus entender o mysterium Christi, o "mistério de Cristo"3. Neste artigo nossa atenção se voltará especificamente para a compreensão da pessoa e obra de Cristo no pensamento de Dietrich Bonhoeffer (1906-1945), teólogo luterano alemão, sem a menor sombra de dúvida, um dos mais importantes e influentes teólogos do século passado e deste início de século XXI.

Nossa primeira afirmação é sobre o quanto a cristologia é importante, mesmo central no pensamento de Bonhoeffer. De fato, a cristologia é como um fio condutor em seu pensamento. Ainda que possa ter havido evolução em seu fazer teológico - este é o pressuposto teórico básico da mencionada tese de Prócoro Velasques Filho - não se poderá negar que em todos os escritos de Bonhoeffer, a cristologia ocupa lugar nuclear. Há decerto diferenças entre os textos mais "evangelicais" de Bonhoeffer - Discipulado, Vida em comunhão, Orando com os Salmos - e os textos mais "progressistas" - Ética e Resistência e submissão. Mas não vemos uma ruptura entre uma e outra fase. Pois há sempre em seu fazer teológico o acento cristocêntrico: o Cristo senhor da vida do cristão em Discipulado, o Cristo senhor do mundo em Ética e Resistência e submissão. Para usar uma expressão do próprio Bonhoeffer, a ênfase cristológica é o cantus firmus da polifonia de sua produção teológica. (BONHOEFFER, 2010, pp. 393-396, 404) Bonhoeffer faz o que Andreas Pangritz, um de seus mais destacados intérpretes, chama de concentração cristológica. No dizer do mesmo Pangritz, “[...] a centralidade de Cristo serve como o motivo decisivo para abrir os horizontes da igreja em direção ao mundo em sua realidade concreta". (PANGRITZ, 1999, pp. 134-135)

O tema da cristologia aparece muito cedo nos escritos de Bonhoeffer. Já em suas aulas a

\footnotetext{
${ }^{2}$ Cf. Mc 8.27-29.

${ }^{3}$ A teologia católica utiliza a expressão "mistério de Cristo", enquanto a tradição evangélica conservadora prefere falar em “doutrina de Cristo". Há uma sabedoria em se referir a Cristo como "mistério”, no sentido que jamais a mente humana será capaz de compreende-lo completamente. A palavra "doutrina" pressupõe explicação de algo que nem sempre está circunscrito pelos limites da razão.
}

Revista Pax Domini | Faculdade Boas Novas | v. 1 | p. 22 - 31 | jun. 2015 
respeito deste capítulo da teologia, ministradas na Faculdade de Teologia da Universidade de Berlim em $1933^{4}$ até suas reflexões mais maduras presentes em Resistência e submissão. O problema central da cristologia para Bonhoeffer é que o Deus-homem, Jesus Cristo, está presente na forma de homoioma sarkos ("semelhança de carne"), isto é, de forma velada. Em Christ the Center ele afirma que isto é uma "pedra de tropeço" e se constitui "no problema central da Cristologia". Para Bonhoeffer o problema, o skandalon, não está na encarnação, pois a encarnação é revelação, isto é, na encarnação Deus se revela aos homens. O problema está na humilhação que ele sofreu na cruz: “O sentido da história está ligado a um evento que acontece na profundidade e ocultabilidade de um homem que terminou na cruz. O sentido da história é encontrado no Cristo humilhado". Bonhoeffer, tal como visto, vai da Cristologia para a eclesiologia. A primeira é a base da segunda. Então o estado de humilhação de Cristo é e deve ser paradigma para a igreja.

Ele usa este ponto para criticar a ideia de uma igreja estatal, uma igreja nacional submissa ao Führer. Na época na Alemanha, tal como anteriormente afirmado, usava-se o slogan "Uma nação, um Reich, uma igreja"5. Caminhando em direção completamente diferente, Bonhoeffer fala que na cruz não vemos ideias abstratas sobre Deus, como onisciência e onipotência. $\mathrm{Na}$ cruz vemos fraqueza. $\mathrm{O}$ homem Jesus não é um Deus abstrato. Mas diante do humilhado, só podemos dizer, 'este é Deus'. Em sua morte ele não manifesta nenhuma das propriedades (= atributos) divinos. Pelo contrário, encontramos um homem em crise ("Deus meu, Deus meu, por que me desamparaste?" 6 ). Todavia, deste homem podemos dizer, "este é Deus"”. Bonhoeffer prossegue: “Como Cristo vai desconhecido, como um pedinte entre os pedintes, um rejeitado entre os rejeitados, um desesperançado entre os desesperançados, um moribundo entre os moribundos - pela mesma maneira, é com este humilhado que a igreja segue seu caminho de humilhação. A igreja não deve lutar pela sua própria afirmação ou confirmação, mas seguir o caminho do humilhado". A igreja deve abrir mão de seus privilégios, pois, como o próprio Cristo, está sujeita ao sofrimento e à fraqueza, por causa de pessoas reais que sofrem no mundo.

Bonhoeffer alinha-se com a cristologia calcedoniana clássica. (BONHOEFFER, 2010, p. 394) Neste ponto, rejeita conscientemente a teologia liberal na qual fora educado, que tinha a tendência de

\footnotetext{
${ }^{4}$ Estas palestras foram publicadas a partir de anotações feitas por seus alunos, e publicadas em forma de livro. Cf. Bonhoeffer, Dietrich. Christ the Center. San Francisco: Harper One, 2009, passim.

${ }^{5}$ Neste sentido, a ênfase dada por Bonhoeffer ao Deus que se revela na cruz, que se revela na fraqueza e na impotência, é um corretivo saudável e necessário a tendências de "teologias do domínio" praticadas por determinadas igrejas pentecostais evangélicas brasileiras que afixam placas na entrada da cidade com dizeres do tipo "A cidade tal e tal é do Senhor Jesus".

${ }^{6} \mathrm{Cf}$. Sl 22.1.
}

Revista Pax Domini | Faculdade Boas Novas | v. 1 | p. 22 - 31 | jun. 2015 
rejeitar o conceito de ousia, "natureza", por ser uma ideia helenizada demais. Ao mesmo tempo, afastase da ortodoxia, com sua tendência de racionalização e teorização extremas do discurso teológico. Para Bonhoeffer, a cristologia é reflexão e adoração do Cristo concreto, real, o Cristo presente, e não uma mera teorização, seja esta em modelo liberal ou ortodoxo. Bonhoeffer fala de Calcedônia como expressão de um mistério que não pode ser explicado. E mesmo sendo luterano convicto, rejeita a doutrina da cristologia luterana clássica conhecida como "comunicação de propriedades", a communicatio idiomatum, que considerou como pura especulação, e que corria risco de ser um monofisismo, por efetivamente negar a plena humanidade de Cristo. A ortodoxia luterana do século XVII (o período da chamada "escolástica protestante", tanto luterana como também reformada) falava do genus majestaticum: a natureza humana de Jesus Cristo se torna "majestática".

Esta é a base para a compreensão luterana do est na doutrina eucarística: Hoc est corpus meum (“Isto é o meu corpo"). Cristo está com, sob e dentro do pão no momento da celebração da eucaristia, ou seja, o que na terminologia teológica clássica é chamado de "consubstanciação". Bonhoeffer então critica esta noção. E apoia a construção reformada chamada pela ortodoxia luterana do século XVII pelo terminus technicus de extra calvinisticum: ${ }^{7}$ a natureza divina de Cristo está além de sua natureza humana. A natureza divina de Cristo não pode ser aprisionada dentro de uma natureza humana, mas permanece infinita a despeito de estar em união com um corpo finito. "O Logos continua em seu relacionamento trinitário e portanto também extra carnem (fora ou além da carne). Finitum incapax infiniti ("o finito não pode conter o infinito"), disse Bonhoeffer em Christ the Center. Na concepção calvinista, Cristo não pode estar presente corporalmente na Ceia do Senhor, porque reina corporalmente nos céus. Sua presença é pneumática, pelo Espírito, e é compreendida existencialmente. Dizem os reformados que o Logos está plenamente unido, mas nunca contido pela natureza humana. Então a encarnação deve ser entendida como além ou fora - extra - da natureza humana.

Bonhoeffer aplaude a ênfase da cristologia calvinista em preservar o que Deus é e o que a humanidade é. Ao mesmo tempo, não abre mão de sua "luteranidade", por assim dizer, e sugere uma fórmula de conciliação: “o finito é capaz de conter o infinito, não por si mesmo, mas com ajuda do infinito!'. Curiosamente, no ano seguinte, 1934, luteranos e reformados assinaram em conjunto a Declaração Teológica de Barmen.

Bonhoeffer alerta para o risco das duas tradições, a sua própria luterana, e a reformada, de rejeitar o ensino das duas naturezas de Calcedônia. Ele vai insistir que as "declarações negativas de

\footnotetext{
${ }^{7}$ A expressão evidentemente remete a João Calvino, mas a ideia já está presente em Agostinho.
}

Revista Pax Domini | Faculdade Boas Novas | v. 1 | p. 22 - 31 | jun. 2015 
Calcedônia são a declaração teológica conciliar ideal”, porque não querem responder a pergunta do "como" (que luteranos e reformados parecem querer responder), mas a pergunta do "quem". Calcedônia, vale repetir, vai dar ênfase ao mistério de Cristo, algo que não pode ser matematicamente explicado.

Para Bonhoeffer o ponto de partida para a inquirição do dogma cristológico é a doxologia, que tem a ver com contemplação e adoração. Isto porque Bonhoeffer reconhece que a fé cristã não é antiintelectual, mas suprarracional. Isto deve fazer da teologia uma tarefa humilde, o que não quer dizer submissão acrítica a ditames eclesiásticos oficiais. Antes, tem a ver com assumir um companheirismo com a humanidade humilhada (a humilhação de Cristo é um ponto central na cristologia bonhoefferiana). A teologia para Bonhoeffer é estar ao lado do ser humano concreto, com suas crises, dores, lutas e problemas. Em um texto com beleza poética e profundidade teológica tremenda (extraído de Bonhoeffer afirma: "A razão teológica é humilhada, e ao mesmo tempo exaltada como um ‘instrumento do louvor da revelação de Deus”. (BONHOEFFER, 2009b)

Para uma compreensão correta de como Bonhoeffer constrói sua cristologia é preciso também um exame de sua proposta hermenêutica, isto é, sua abordagem ao texto bíblico. Pois, conforme já dito, mesmo tendo ele sido um teólogo sistemático, sua teologia dialoga com o texto bíblico mais que com mediações conceituais filosóficas ${ }^{8}$. Bonhoeffer traça paralelos entre a narrativa de Davi no livro de Samuel com a narrativa de Jesus nos Evangelhos. Três exemplos são dignos de menção:

1) A entrada de Davi em Jerusalém como rei e a entrada de Jesus em Jerusalém em humildade. Ao assim fazer, Bonhoeffer tece crítica clara às pretensões idolátricas do Führer alemão;

2) A promessa de Deus de estabelecer casa para Davi (cf. $2 \mathrm{Sm} 7$ ), que encontra cumprimento na igreja, que é o corpo de Cristo, descendente de Davi;

3) Os pecados de Davi: até neste ponto Bonhoeffer vê em Davi uma imagem, um "exemplo e sombra" do Cristo crucificado, que assume nossos pecados. Percebe-se aí claramente a influência de Lutero no pensamento de Bonhoeffer: se Jesus assumiu nossos pecados na cruz, na cruz encontramos o Cristo ladrão, assassino, mentiroso, adúltero, ou seja, o pecador.

A partir daí, podem ser feitas algumas observações:

\footnotetext{
${ }^{8}$ A exceção disto está em Akt und Sein, sua tese de Habilitação para a docência, na qual dialoga extensamente com a filosofia, notadamente com o pensamento de Kant, Hegel e Heidegger.
}

Revista Pax Domini | Faculdade Boas Novas | v. 1 | p. 22 - 31 | jun. 2015 
1) A interpretação que Bonhoeffer faz do Antigo Testamento a partir de Cristo, é tipológica, não alegórica: Davi é um tipo de Cristo, uma figura, para usar a terminologia de Erich Auerbach, crítico literário alemão (AUERBACH, 1997).

2) A hermenêutica bíblica de Bonhoeffer revela sua "luteranidade", expressa no já mencionado método hermenêutico de Lutero, que tinha a pessoa de Cristo como chave de interpretação das Escrituras. Seu princípio interpretativo, tal como já afirmado, é Was Christum Treibet - "o que exalta a Cristo". A Escritura é vista como a "manjedoura na qual está o bebê Cristo. Se não encontramos Cristo, encontramos palha" (e a palha deve ser desprezada).

3) A interpretação cristológica do Antigo Testamento por Bonhoeffer é uma defesa da tentativa de reconfiguração do Cristianismo em moldes arianos. O movimento dos Deutsche Christen propunha uma releitura do Cristianismo na qual todos os elementos judaicos seriam expurgados. Jesus seria visto como um herói que teria lutado contra o Estado judeu. Bonhoeffer, com sua proposta de interpretação bíblica que valorizava o Antigo Testamento, afirmou com convicção que não pode haver Cristianismo sem a Bíblia Hebraica. Desta maneira, entrava em rota de colisão frontal com os interesses do Nacional-Socialismo;

4) Bonhoeffer inverte a maneira tradicional pela qual a tradição cristã, protestante e católica igualmente, lê a Bíblia Hebraica. A tendência cristã é ler o Antigo Testamento à luz do Novo Testamento. A tradição reformada de leitura bíblica por exemplo, que Bonhoeffer muito provavelmente conhecia, lê as Escrituras seguindo um esquema de promessa e cumprimento: a promessa do Antigo Testamento encontra cumprimento na pessoa de Cristo no novo Testamento. Todavia, Bonhoeffer diz que devemos fazer o contrário. É a sua famosa dialética das últimas e das penúltimas coisas: não se pode falar a última palavra - o Novo Testamento - sem a penúltima - o Antigo Testamento. Só se pode evocar o nome de Cristo quando se compreende que na tradição judaica o nome de Deus não era sequer pronunciado. Esta tendência é útil, porque existe uma tendência, pelo menos em círculos evangélicos, de quase desprezar o Antigo Testamento. Bonhoeffer propõe ousadamente uma leitura cristológica das Escrituras que valoriza devidamente as Escrituras hebraicas;

5) Como consequência direta de sua proposta de leitura bíblica, Bonhoeffer repensou a noção de salvação. O tema é sem dúvida importante. A questão soteriológica foi o "estopim” para Lutero iniciar seu programa reformador. Bonhoeffer então, coerente com seu programa hermenêutico, propõe um completo repensar da doutrina da salvação. Se é para falar a penúltima palavra para só então falar a última, não se poderá falar de salvação como se fosse temas apenas do Novo Testamento: na Bíblia

Revista Pax Domini | Faculdade Boas Novas | v. 1 | p. 22 - 31 | jun. 2015 
Hebraica, salvação é deste lado da morte, não apenas uma experiência pós-morte, tal como pensado pelo cristianismo medieval, e até hoje na maioria das igrejas, tanto a católica como as da Reforma. Bonhoeffer então propõe reimaginar a salvação em termos mundanos, terrenos. Em uma carta datada de 5 de maio de 1944 enviada a Eberhard Bethge ele diz:

\footnotetext{
No momento estou pensando em como os conceitos de arrependimento, fé, justificação, novo nascimento e santificação, devem ser reinterpretados de maneira "mundana" - no sentido do Antigo Testamento e no sentido de João 1.14. (BONHOEFFER, 2010, p. 373)
}

Todavia, não há como saber como seria isto, pois Bonhoeffer foi prematuramente levado pela morte, o que torna sua "teologia de Tegel” fragmentária e incompleta.

A propósito, a "concentração cristológica" de Bonhoeffer continua presente em suas "cartas da prisão”. Prova eloquente é a famosa questão que ele levanta em uma carta ao amigo Eberhard Bethge de 30 de abril de 1944 (praticamente um ano antes de sua morte): "O que continua me perturbando é a pergunta, o que é o cristianismo, ou quem é na verdade Cristo para nós hoje?”. (BONHOEFFER, 2010, p. 362) Conforme já afirmado, a questão cristológica par excellence para Bonhoeffer é a questão do senhorio de Cristo. Mas eis que em sua cela de prisão uma interrogação séria lhe vem à mente: como Cristo é Senhor em um mundo adulto, ou emancipado (Die Mundige welt)?.

No dia seguinte (21/07/44) ao golpe fracassado contra Hitler, Bonhoeffer escreveu para Bethge: "Mais tarde descobri, e ainda estou descobrindo até hoje, que só se aprende a ter fé na plena mundanidade da vida”. (BONHOEFFER, 2010, p. 486) Para Bonhoeffer há que se viver esta "mundanidade", que consiste em "participar nos sofrimentos de Deus na vida secular" e permitir-se "participar dos sofrimentos messiânicos de Deus em Jesus Cristo". Bonhoeffer descreve estes sofrimentos messiânicos como o cumprimento de Isaías 53, o sofrimento do "servo de Javé", que a tradição judaica sempre entendeu como tendo cumprimento no próprio povo de Israel. (BONHOEFFER, 2010, p. 480) A participação cristã nos sofrimentos de Cristo é realizada em solidariedade com o povo de Israel e com todos que são levados como ovelhas para o matadouro. Esta compreensão de vida cristã é decorrência e consequência de sua cristologia.

Desta maneira a cristologia de Bonhoeffer, construída de maneira a um só tempo fiel à tradição e original, é a base para sua compreensão de igreja e desembocará em sua compreensão da ética. A ética de Bonhoeffer não é uma ética moralista nem casuística. Antes, é uma ética da responsabilidade

Revista Pax Domini | Faculdade Boas Novas | v. 1 | p. 22 - 31 | jun. 2015 
do ser humano para com o próximo, o semelhante. Em Bonhoeffer encontra-se exemplo notável de coerência entre biografia e teologia: em seguimento de Cristo, que revela Deus, ele se posicionou ao lado dos mais perseguidos da sociedade do seu tempo - no caso, os judeus. Antes, há que se registrar, Bonhoeffer tomara a ousada - e perigosa - decisão de trabalhar para a Abweher, a agência de inteligência alemã, liderada pelo Almirante Wilhelm Canaris, que na verdade era um opositor de Hitler. Em 1942, valendo-se das prerrogativas de funcionário da Abwehr, Bonhoefer auxiliou um grupo de 14 judeus alemães para que escapassem para a Suíça, neutra na guerra, no que ficou conhecido como Unternehmen 7, “Operação 7”. (HAYNES, 2007, p. 45) Só que os espiões eram espionados: havia uma rixa entre a Abwher e a Gestapo, e esta última descobriu o envolvimento de Bonhoeffer com a citada empreitada que deu fuga ao citado grupo de judeus. Bonhoeffer foi preso. Juntamente com ele, o citado Almirante Canaris, o General Hans Oster, que também trabalhava para a Abwehr, e Hans von Dohnanyi, casado com Christine Bonhoeffer, uma das irmãs de Dietrich. Bonhoeffer foi levado para a prisão militar de Tegel, onde ficou por cerca de um ano e meio. Preso, continua a escrever Ética 9 (ele já trabalhava no manuscrito desta obra em 1940, quando passou um tempo no mosteiro beneditino de Ettal, nas imediações de Munique, em uma espécie de retiro espiritual) e muitas das cartas e textos que foram postumamente publicados com o título Resistência e submissão ${ }^{10}$.

No dia 8 de abril de 1945 foi emitida a sentença de morte do prisioneiro Bonhoeffer, por ordem direta do próprio Hitler. No dia seguinte ele foi executado, por enforcamento (para prolongar a dor e o sofrimento), juntamente com o Almirante Canaris e o General Oster. A caminho da forca pronunciou suas últimas palavras: Das ist das Ende - für mich der Anfang des Lebens - "Este é o fim - para mim, o início da vida".

\section{CONSIDERAÇÕES FINAIS}

Em Bonhoeffer a eclesiologia e a ética são derivadas da cristologia. E a cristologia de Bonhoeffer não é abstrata, meramente especulativa. Antes, é uma cristologia da ação, da práxis, para usar uma palavra muito importante na teologia latino-americana (que, a propósito, foi muito

\footnotetext{
9 Bonhoeffer, Ética. 9a edição. São Leopoldo: Sinodal, 2009. Ver também Ethics. Dietrich Bonhoeffer Works, English. Volume 6. Minneapolis: Fortress Press, 2008 (título original: Ethik).

${ }^{10}$ Bonhoeffer, Resistência e submissão. São Leopoldo: Sinodal, 2003. Ver também Letters and Papers from Prison. Dietrich Bonhoeffer Works, Volume 8. Minneapolis: Fortress Press, 2010 (título original: Widerstand und Ergebung. Briefe und Aufzeichungen aus der Haft).
}

Revista Pax Domini | Faculdade Boas Novas | v. 1 | p. 22 - 31 | jun. 2015 
influenciada pela teologia de Bonhoeffer, tanto a teologia ecumênica protestante como a teologia da libertação católica; a teologia latino-americana de corte evangelical também recebeu influência considerável de Bonhoeffer). Daí conclui-se que falar de cristologia em Bonhoeffer leva a falar sobre ética e sobre eclesiologia. Pois em Bonhoeffer, não é demais repetir, ética e eclesiologia estão baseadas em sua cristologia. Sua concepção cristológica é simplesmente fundamental para a compreensão de como devem o cristão individual - ética - e a igreja, comunidade dos seguidores de Jesus Cristo no mundo - eclesiologia - agir na sociedade. Em todo o tempo, Cristo é o modelo e o critério de julgamento das nossas ações.

Com Bonhoeffer aprendemos uma ética não moralista, não utilitarista, mas uma ética da responsabilidade do cristão para com o seu semelhante.

Com Bonhoeffer aprendemos que a igreja deve existir e viver não para si mesma, como se vê com muita frequência, mas para o outro, para o próximo, especialmente o próximo em situações de vulnerabilidade e fragilidade.

Para Bonhoeffer a vida cristã é Nachfolge - "seguimento" - de Cristo, ou seja, discipulado. A compreensão cristológica de Bonhoeffer o levou a ações concretas em favor dos mais necessitados de sua sociedade. O que nos leva, ou deve nos levar, a pensar, em nossa própria atuação como cristãos brasileiros neste início de século XXI. Considerável parte do evangelicalismo brasileiro nos últimos poucos anos (pelo menos grupos que têm maior visibilidade midiática) apresentam uma versão estranha de um Christus Victor, não no sentido clássico de setores da igreja primitiva, mas, esquizofrenicamente, um Cristo que é vitorioso sobre a doença e os problemas financeiros, mas ao mesmo tempo é um Cristo reduzido a uma espécie de "gênio da lâmpada", poderoso, mas na prática é obrigado a atender a todos os pedidos e desejos dos fiéis, desde que estes paguem devidamente suas ofertas e dízimos. Nas igrejas e movimentos religiosos que abraçaram este tipo de discurso não há espaço para o discipulado. Bonhoeffer é por conseguinte um corretivo saudável para um tempo em que fala-se de Cristo, mas não o Cristo da revelação bíblica.

Bonhoeffer, em sintonia com o testemunho da revelação bíblica e com toda a longa tradição do cristianismo ortodoxo, enfatiza Cristo como o revelador de Deus. Mas ao estudar sobre Cristo, inevitavelmente nos deparamos com a cruz. E no escândalo e vergonha da cruz, descobrimos o Deus Conosco, o Emanuel, que se faz solidário com as vítimas, os sofredores, os injustiçados, os derrotados da vida e do mundo. Bonhoeffer segue Lutero bem de perto, com sua theologia crucis, "teologia da cruz". Com Bonhoeffer e de Bonhoeffer aprendemos sobre o Cristo solidário, que se fez vítima -

Revista Pax Domini | Faculdade Boas Novas | v. 1 | p. 22 - 31 | jun. 2015 
"somente um Deus que sofre pode ajudar".

A ênfase luterana no Deus crucificado adquire especial importância em Bonhoeffer. Esta ênfase cristológica bonhoefferiana também serve de corretivo para grupos evangélicos que se vangloriam de confessar uma cristologia ortodoxa, correta, mas que acaba caindo no extremo oposto ao Cristo do Neopentecostalismo, pois se trata de um Cristo distante, no céu. A formulação doutrinária pode ser correta, mas efetivamente tem pouca aplicabilidade pastoral, especialmente diante de situações de crise. Vemos então no Brasil contemporâneo dois extremos quanto ao entendimento da pessoa de Cristo e de sua obra: o caso da distorção da ideia da realeza de Cristo, apresentada no Neopentecostalismo, e também o caso de grupos ortodoxos, que se gabam de sua correção doutrinária, mas que acabam por apresentar um Cristo distante. A cristologia de Bonhoeffer oferece um corretivo saudável para as duas situações.

\section{REFERÊNCIAS BIBLIOGRÁFICAS}

\section{FONTES PRIMÁRIAS}

BONHOEFFER, Dietrich. Ética. $9^{a}$ edição. São Leopoldo: Sinodal, 2009a . Ethics. Dietrich Bonhoeffer Works, English. Volume 6. Minneapolis: Fortress Press, 2008 . Resistência e submissão. São Leopoldo: Sinodal, 2003

. Theological Education Underground: 1937-1940. Dietrich Bonhoeffer Works, English.

Volume 15. Minneapolis: Fortress Press, 2009b

Christ the Center. San Francisco: Harper One, 2009c

. Letters and Papers from Prison. Dietrich Bonhoeffer Works, Volume 8. Minneapolis: Fortress Press, 2010

\section{FONTES SECUNDÁRIAS}

AUERBACH, Erich. Figura. São Paulo: Ática, 1997.

HAYNES, Stephen R. "Bonhoeffer, the Jewish People and Post-Holocaust Theology: Eight Perspectives; Eight Theses". Studies in Christian-Jewish Relations. 2/1 (2007):36-52. Disponível em http://ejournals.bc.edu/ojs/index.php/scjr/article/viewFile/1401/1291 [acesso: 19 de setembro de 2015]. PANGRITZ, Andreas. "Who is Jesus Christ for us today?” In DeGruchy John (org.). The Cambridge Companion to Dietrich Bonhoeffer. Cambridge: Cambridge University Press, 1999

Revista Pax Domini | Faculdade Boas Novas | v. 1 | p. 22 - 31 | jun. 2015 